\title{
HOMENAGEM A ECLÉA BOSI ${ }^{1}$
}

\section{Marilena Chauí}

Resumo: Neste ensaio, buscamos a principal contribuição de Ecléa Bosi para a Psicologia Social, qual seja, a relação entre teoria, método e técnicas de pesquisa e militância social, política e cultural, a partir da definição da psicologia como fenomenologia dos atos expressivos e da relação de amizade entre o pesquisador e o pesquisado como pessoa.

Palavras-chave: Psicologia social. Memória. Dignidade do outro. Ética na pesquisa. Militância.

Fiquei muito comovida, muito honrada, quando a Viviana me telefonou e perguntou se eu falaria na homenagem que a Universidade, o Instituto de Psicologia e a Psicologia Social iam prestar a você. Eu disse que sim, sem dúvida, que era uma felicidade poder participar. Depois, e como sempre acontece comigo, porque digo primeiro sim, só depois avalio as conseqüências, eu me perguntei: o que eu vou falar? E foi engraçado, porque eu estava arrumando livros que foram do meu pai (livros que eu mandei encadernar para guardar para mostrar para meus netos), e entre esses livros há um que me fascina desde que eu era muito pequena, cujo um título me impressionou e que demorei muito para ter coragem de abrir, um livro enorme, escrito em 1942, ainda sob os efeitos da ocupação nazista na Holanda, escrito por Hendrick Van Loon, intitulado Vidas ilustres e eu pensei:"vou falar de uma vida ilustre, é disso que eu precisava".

No livro de Van Loon, são imaginados encontros entre personagens célebres, que são convidadas para vários jantares. Uma vida ilustre é narrada mesclando biografia e obra, fatos curiosos e pouco conhecidos, comentados pelos convivas. Por isso, 
ao me preparar para falar de uma vida ilustre, pensei: "vou coligir lembranças dos meus contatos com Ecléa, a começar pela primeira coisa que eu soube dela".

Por volta de 1967, quando vi a Ecléa e o Alfredo pela primeira vez, na casa de Lúcia e Bento Prado, a Lucia me disse: "Aquela é a Ecléa Bosi. Ecléa não toma aspirina porque a Bayer se comprometeu com os campos de concentração nazista". Isso para mim definiu para sempre a Ecléa. Da recusa da aspirina, ontem, à luta contra as usinas nucleares, hoje, ela é capaz de atitudes e gestos que, enquanto tais, não mudam o mundo e, no entanto, exigem uma mudança completa de nossa relação com o mundo. Exatamente como Espinosa pensa a virtude: esta não muda o mundo e sim a nossa relação com ele. É o sentido do mundo que se transforma em nós e para nós; e essa mudança poderá, quem sabe?, mudar alguma coisa no mundo.

Depois, ainda sob a inspiração de Van Loon, eu me disse que não se tratava simplesmente de minha memória sobre esta memorialista, mas sobretudo de sua obra, do trabalho que ela fez e faz e, portanto, de seu percurso e de sua contribuição para a Psicologia Social e para o pensamento brasileiro.

Tive, então, uma dúvida. Seria melhor tomar de volta os memoriais que ela escreveu para os concursos de livre-docência e adjunção - de cujas bancas participei - e, a partir deles, falar de seu trabalho? Ou seria mais interessante ir a esta coisa fantástica, complicada, odiosa e necessária que é o curriculum Lattes? Depois desses rodeios, decidi que não era nada disso, que eu queria falar do seu trabalho como uma decisão de vida e uma decisão de vida cujas conseqüências éticas, políticas, intelectuais e acadêmicas são monumentais. Por esse motivo, vou fazer uma intervenção que espero seja curta, mas cujo núcleo é a passagem sem solução de continuidade ou o movimento contínuo que vai de sua interpretação das leituras das operárias, passa pelas memórias de velhos, chega à formação de comunidades de leitores e alcança a Universidade Aberta à Terceira Idade.

Certa vez, Ecléa me presenteou com um livro chamado A Firmeza Permanente. Eu quero, aqui, falar do traço mais marcante de Ecléa: a coerência permanente, uma voz tensa como um sino que repica alegremente para, de súbito, soar com a gravidade de um dobre prolongado do qual, de repente, salta uma nova nota, uma badalada cheia de esperança.

Na página final da sua primeira obra, Cultura de Massa e Cultura Popular: Leituras de Operárias, Ecléa indagava sobre o significado do trabaIho que ela havia acabado de realizar. Vocês se lembram, ela propõe, numa perspectiva gramsciana, uma discussão em torno da questão da cultura de massa, da cultura popular, da cultura erudita, analisa a posição de Umberto Eco e, após esse percurso, ela introduz a idéia de uma cultura de proposta, que se erga contra a cultura de entretenimento, e conclui:

Como situar esse trabalho no conjunto destas análises [sobre a questão da cultura]? Conscientes do pouco que fizemos, acreditamos, contudo, que devem 
ter uma significação as respostas destas moças que interromperam sua jornada e vieram conversar conosco de suas modestas leituras e aspirações. Escrever é desvendar o mundo, ensina Sartre, e oferecê-lo como uma tarefa à generosidade do leitor. Desejamos que do trabalho se depreenda um objetivo. Esta pesquisa foi realizada na véspera, antes dos fatos, isto é, antes da formação de uma comunidade de leitores. Devemos trabalhar para a sua existência, através da formação de bibliotecas de bairro, de paróquias, de fábricas. Depois de descobrir carências, percebemos que elas nos comprometem. É preciso conhecer o problema de perto, tocar nos fatos. Mas isto não basta para que se fale em nome de alguém: devemos também enxergar de sua perspectiva a realidade.

Assumir uma visão operária do mundo, é um exercício difícil, um limite que tentamos alcançar, um caminho a percorrer. (Bosi, 1981, p. 179)

Embora difícil e embora encontre resistência intolerante, esse exercício se define, por um lado, contra a crítica aristocrática aos meios de massa e a cegueira quanto ao seu perigo e, de outro, por uma verdadeira palavra de ordem, endereçada à "comunidade dos homens de cultura", para que se constitua num grupo de pressão cultural. Em outras palavras, a pesquisa realizada desemboca em ações concretas - formação de comunidades de leitores, de bibliotecas de bairro, de paróquia e de fabrica, grupos intelectuais de pressão contra a cultura de massa.

A indagação de Ecléa e a busca de uma resposta configuram uma tomada de posição ética e política sobre a atividade intelectual e a pesquisa científica como militância, compromisso de luta contra a violência cotidiana da sociedade capitalista, em geral, e da brasileira, em particular. Mulheres operárias, que desejam ler e às quais são oferecidas tanto uma falsa biblioteca de enciclopédias baratas e mal-feitas quanto revistas malimpressas e fáceis romances amorosos; mulheres cuja vista cansada dificulta a leitura desejada, e que a fadiga faz dormir sobre os livros.

É esse caminho de luta que se exprime naquilo que podemos considerar o foco de sua obra seguinte, Memória e Sociedade, quando escreve: "O velho não tem armas. Nós é que temos de lutar por ele" (Bosi, 1994, p. 81). Se os velhos são os guardiães do passado, por que somos nós a lutar por eles? Porque foram desarmados. Ao nos conduzir até os idosos pobres e solitários, abandonados como os últimos vestígios da cidade, Ecléa expõe uma ferida aberta em nossa sociedade: a velhice despojada, oprimida e banida. Impedidos de lembrar e de aconselhar, impedidos de unir o começo e o fim, o passado e presente, em nossa sociedade - pragmática e consumida pelo desejo de eterna juventude veiculado pela cultura de massa --, os velhos precisam lutar pelo direito de continuar humanos.

Ao debruçar-se sobre a experiência e o testemunho destes dois grupos de pessoas, Ecléa sinalizou e marcou para sempre o campo da Psicologia Social brasileira, dando-nos a ouvir vozes e fisionomias que a sociedade de classes e a cultura de massa forçam ao silêncio e à obscuridade. $O$ sinete de Ecléa não se restringe, porém, a dar visibilidade ao invisível e voz ao si- 
lêncio, mas prossegue como uma ação transformadora. Da pesquisa sobre a leitura das operárias paulistanas nasce uma política cultural de leitura com a formação das comunidades de leitores e da reinvenção do espaço público das bibliotecas, trabalho de que tive a honra de participar quando Ecléa propôs a realização deste projeto no período em que, na Secretaria Municipal de São Paulo, pude contribuir para concretizá-lo. Da pesquisa sobre a memória dos idosos nasce a Universidade Aberta à Terceira Idade, cujo objetivo é possibilitar ao idoso aprofundar conhecimentos em alguma área de seu interesse e, simultaneamente, trocar informações e experiências com os jovens, reatando o fio do tempo para refazer o tecido que entrelaça passado e presente.

Da pesquisa sobre a leitura das operárias nasce a busca da compreensão do sentido da cultura operária e da cultura popular, no interior da sociedade de classe e da cultura de massa. Da pesquisa sobre a memória dos idosos nasce a critica da situação da velhice na sociedade industrial e surge o resgate do lugar afetivo e civilizatório dos idosos, enfatizado pela proposta de uma nação em que o contato com os jovens seja central para a troca de experiências, conhecimentos, informações. Como ela escreve em O Tempo Vivo da Memória, a memória não é um repositório de lembranças e sim uma atividade do espírito, "um trabalho sobre o tempo, mas sobre o tempo vivido, conotado pela cultura e pelo indivíduo" (Bosi, 2003a, p. 53).

Do que se trata esses dois casos? Da afirmação da dignidade do outro e de tudo o que a sociedade perde quando incapaz de reconhecê-la e afirmá-la. Essa dignidade revela que a Psicologia Social praticada por Ecléa recusa reduzir o outro à condição do objeto de pesquisa. Reduzir um humano à condição de objeto é praticar a violência, pois esta é a violação da essência de um ser, tratando como irracional, insensível e mudo aquele que é racional, sensível e falante. Ao recusar a subjetividade e a personalidade do outro, essa redução, ato de violência, impossibilita a ética. Ao contrário, ao tratá-lo como alguém, como pessoa e sujeito, Ecléa tece um laço de amizade como outro, foco e centro de suas orientações de pesquisa.

Passo, então, a OTempo Vivo da Memória, no qual a posição científica, filosófica, ética e política de Ecléa se transmite aos seus alunos e orientandos com seu trabalho como formadora, professora e orientadora, instituindo uma tradição no sentido forte da palavra.

De suas obras anteriores e desse último livro, destaco, em primeiro lugar, o trabalho teórico realizado por Ecléa e transmitido aos novos pesquisadores em Psicologia Social. Partindo da complexidade conceitual e real da memória, tomada como totalização temporal, Ecléa explora essa complexidade ao reunir as contribuições da teoria da Gestalt - a existência de campos de significações na vida subjetiva e na vida intersubjetiva -, da filosofia bergsoniana - a dimensão temporal inerente à memória -, da filosofia de Hegel - o passado concentrado no presente -, da psicologia social, particularmente de Halbwachs - o papel das relações com a família, 
o grupo cultural, a classe, a comunidade para a interpretação dos dados -, da filosofia de Benjamin - particularmente a figura do narrador e o caráter redentor da memória -, e da filosofia dialética (Marx e Adorno sobretudo) para a compreensão do fenômeno das ideologias. Quanto às técnicas de pesquisa, ela é peremptória: "é a lei do outro. Não conheço outra".

Por isso mesmo, menciono aqui o momento em que Ecléa tematiza a relação do pesquisador com o outro como alguém. Antes de mais nada, diz ela, é preciso que o estudioso compreenda "o depoimento como um trabalho do idoso". Em seguida, explicita as condições adequadas em que a experiência com o entrevistado poderá permitir a realização desse trabaIho memorioso e de sua escuta; passa às condições em que o pesquisador deverá exercitar a interpretação: a evocação biográfica como tapeçaria e jogo de claro-escuro que apontam para "focos de atração na paisagem"; a percepção e compreensão de limites e fronteiras geradores de tensão e conflitos para o memorialista; a sensibilidade para captar a intenção que configura a narrativa, estar atento aos silêncios, aos lapsos, às incertezas do narrador, pois "a fala emotiva e fragmentada é portadora de significações que nos aproximam da verdade", e o estudioso que se põe à escuta não pode ignorar que lida com o esquecimento e a perda; o direito do narrador de receber de volta sua narração, pois assim como o intelectual, ao escrever, apaga, modifica, volta atrás, assim também, no trabalho da memória o memorialista tem o direito de mudar o que narrou.

Tanto a elaboração conceitual como a da técnica de escuta e interpretação são pensadas por Ecléa como capazes de desaguar na compreensão crítica das causas históricas que determinam a memória, desde que a interpretação esteja guiada por um projeto, pois "o passado reconstruído não é refúgio, mas uma fonte, um manancial de razões para lutar. A memória deixa de ter um caráter de restauração e passa a ser memória geradora de futuro".Em outras palavras, a dimensão militante do trabalho intelectual é a bússola, cuja agulha é "a lei do outro" e cujo norte é a geração do porvir.

Ao reconstruir caminhos de sua pesquisa, a militância ou coerência permanente de Ecléa assim se exprime:

Faz alguns anos recolhi a memória do tempo, do espaço, a memória política, a memória de trabalho de velhos moradores de São Paulo. Conversei longo tempo com eles e enquanto ouvi as suas narrativas ia aprendendo alguma coisa sobre a situação da velhice na sociedade industrial -- tema dos mais dignos de ser estudado por militantes políticos e culturais. A memória dos velhos desdobra e alarga de tal maneira os horizontes da cultura e faz crescer junto com ela o pesquisador e a sociedade onde ele se insere.... Se alguém colhe um grande ramalhete de narrativas orais, tem pouca coisa nas mãos. Uma história de vida não é feita para ser arquivada ou guardada numa gaveta como coisa, mas existe para transformar a cidade onde ela floresceu. A pedra de toque é a leitura critica, a interpretação fiel, a busca do significado, que transcende aquela biografia: é o nosso trabalho e muito belo seria dizer, a nossa luta. (Bosi, 2003a, p.69) 
Ecléa define a Psicologia como uma fenomenologia dos atos expressivos. Isto significa, antes de mais nada, que a Psicologia lida com campos de presença e que esta institui campos de sentido. Porque se trata de sentido, não temos coisas nem estamos diante de objetos. Há seres humanos em ação. Mas, justamente, porque se trata de atos expressivos, isso é, porque se trata de expressão, trata-se da criação de significações, de maneira que o sentido instituído pelo campo de presença exige interpretação e, portanto, o trabalho do psicólogo social. Há, assim, uma definição da Psicologia dotada de quatro dimensões simultâneas: a figura do outro, a figura do pesquisador, a forma de relação entre ambos e o modo de trabalhar de cada um deles. Um ato expressivo é um campo de presença e cria significações.

Penso que nessa definição da Psicologia entrecruzam-se alguns dos aspectos mais notáveis do pensamento de Ecléa Bosi. O campo de presença e de sentido se realiza como aquilo que, na Fenomenologia da Percepção, Merleau-Ponty chama de reflexão em outrem. Esta é provavelmente uma das mais curiosas, das mais instigantes expressões que um filósofo pode criar, na medida em que, por definição, a reflexão é a volta do sujeito sobre si, é a relação dele consigo mesmo, é de alguma maneira o seu fechamento sobre si. O paradigma da reflexão, como sabemos, encontra-se em Descartes quando, nas Meditações Metafísicas, propõe fechar os olhos, tapar os ouvidos, fechar a boca, insensibilizar o tato e mergulhar na mais completa e perfeita solidão, deixando que o seu pensamento fique à sós consigo mesmo, volte-se sobre si e enuncie a primeira verdade filosófica: "Penso, existo". É este o modelo canônico da reflexão, a volta silenciosa de si sobre si mesmo. Conseqüentemente, parece descabida e desprovida de sentido a expressão merleaupontyana reflexão em outrem. A reflexão, por princípio, corta a relação com o outro. Porém, com a expressão reflexão em outrem, Merleau-Ponty pretende apanhar o significado primordial ou originário da reflexão: só compreendo o sentido do meu pensamento e o sentido das minhas palavras se eles me são dados pelo outro. Eu sei de mim quando o outro, falando de si mesmo, ensina para mim o que estou dizendo e o que estou pensando - a palavra do outro ensina-me o sentido da minha, o pensamento do outro ensina-me o sentido do meu e sua presença ensina-me sobre meu próprio ser. Acredito que a reflexão em outrem é o núcleo duro do trabalho de Ecléa Bosi. É isto que ela faz: na prática, como método, e na teoria, como disposição filosófica e científica. Foi o que buscou, ao propor uma visão operária do mundo segundo as próprias operárias, ou uma visão da cidade, do tempo, da vida e da história segundo a fala dos próprios idosos. Não buscou produzir um discurso sobre elas e eles, mas deixar falar o discurso delas e deles.

$\mathrm{E}$, eu penso que a reflexão em outrem corresponde ao que Simone Weil chama de atenção, tal como Ecléa a pensa: 
Para Simone Weil, a atenção é uma forma alta de generosidade. Todas as outras vantagens da instrução são secundárias comparadas ao exercício da atenção: é um bem em si, independente de recompensa ou aquisição de informações. Os estudos são nada mais que uma ginástica da atenção seja qual for o seu conteúdo. Ela nos convida a privar tudo, que chamamos de eu da luz da atenção e transferí-la para o que está fora de nós (movimento contrário de certa psicologia que procura escavar os poços do ego na história individual). (Bosi, 2003a, p. 211)

Ou seja, a atenção como a reflexão em outrem propõem um movimento contrário a uma psicologia subjetivista ou solipsista, de estilo cartesiano, uma psicologia da posse de si. A reflexão em outrem, diz Merleau-Ponty, é o contrário da posse de si. Por sua vez, "Simone Weil nos recomenda", prossegue Ecléa,"a que agucemos nossas faculdades para entregar-nos através do olhar e da escuta ao que é secreto, silencioso, quase invisível" (Bosi, 2003a, p. 211). E que só nos chegam pelo outro.

Merleau-Ponty afirma que a reflexão em outrem é um movimento que instaura a identidade do sair de si e do entrar em si. E esta identidade da exteriorização e da interiorização, diz ele, é o que se chama verdadeiramente espírito. Ora, a identidade do sair de si e do entrar em si, da exteriorização e da interiorização é o que Ecléa chama de trabalho. Trabalho do memorialista, trabalho da escuta, trabalho do silêncio e do fragmento, trabalho da interpretação, trabalho da crítica e trabalho da luta.

Há ainda um outro aspecto que me parece relevante para captarmos a obra de Ecléa Bosi. Definir a Psicologia como fenomenologia dos atos expressivos significa afirmar que o campo de presença e de sentido se realiza como diálogo. As palavras do outro ensinam-me as minhas e as suas idéias ensinam-me meu pensamento. Só tenho acesso a mim mesma pela doação do outro e de mim a ele no diálogo. Isto confere à escuta um lugar e uma gravidade insuspeitados. É isto que Simone Weil nos ensina quando diz que não escutaremos a palavra e o silêncio se não formos capazes de ouvir aquilo que os constituem, que lhes dá sentido, que permite a fadiga. É isso que Ecléa nos ensina quando nos mostra o equívoco preconceituoso da noção de "código restrito", atribuída à cultura dos pobres, e nos propõe a idéia grandiosa de código conciso, no qual a palavra, todos os gestos que a acompanham, as suas franjas de indecisão, ambigüidade, silêncios e labirintos exprimem uma significação.

Um último aspecto que gostaria de mencionar quanto à definição da Psicologia por Ecléa se refere ao campo de presença como trabalho da instituição do sentido enquanto tempo. O tempo - Ecléa nos mostra isso tanto no seu livro sobre Memória e Sociedade como neste último livro dedicado ao Tempo Vivo da Memória - não é uma sucessão de instantes: não é um escoamento do passado para o presente, do presente para o futuro. 0 tempo como sucessão e como escoamento é espaço não é tempo. A visão espacializada do tempo perde o trabalho temporal, a instituição do senti- 
do como temporalidade.O tempo é, em sentido fenomenológico, inquietação, ausência de quietude. É puro movimento. O tempo, diz Merleau-Ponty é pura diferença ou a diferença interna de si consigo. Lembrar é diferenciar. Esquecer é desdiferenciar. $O$ tempo é a abertura infinita e transcendência, nos ensina Ecléa. É como a luz, que dá a ver e é também aquilo que é visto. Assim, Ecléa mostra que o tempo é o sentido como presença ausente e como ausência presente. $O$ tempo é o sentido exatamente sobre os dois pássaros de Simone Weil, lembrado por Ecléa:

Simone amava os poemas litúrgicos védicos que se referem à árvore do mundo, a figueira eterna, ao Açvatthá.

Nela estão pousados dois pássaros: um que come seus frutos, outro que olha e não come.

O pássaro que não come o fruto presta atenção. Sua renúncia partilhará e multiplicará os frutos saborosos para todos nós.

É o espírito testemunha, que vê o outro consumir num instante, a vontade devoradora e passional que não será instrumento de salvação se não for acompanhada pelo olhar, pela escuta, pela atenção... e pela renúncia à posse do resultado.

Essa dualidade para Simone Weil -- olhar e consumir -- como duas operações diferentes -- constitui a dor, da vida humana. Comer, ter fome, consumir, ter fome... eis a cadeia do sofrimento.

A felicidade seria se elas fossem o mesmo. Se fossemos nutridos pelo que contemplamos. A dor nasce da cisão entre comer e olhar, consumir e contemplar, a possessão e a atenção. (Bosi, 2003a, pp. 218-219)

Mas eu penso que, ao contrário da dor e do sofrimento, dessa dualidade que se impõe a Simone Weil, a transcendência e a abertura da infinitude do tempo, como sentido e trabalho, que aparece na obra de Ecléa, nos asseguram a passagem desta dor e deste sofrimento à possibilidade da identidade, à possibilidade da felicidade.

Essa Ecléa que nos dá a ver o invisível e a ouvir o silêncio, que não recua diante das perdas e dos desenraizamentos, que não recusa, em instante nenhum, a militância por um mundo outro, é uma Ecléa que luta teimosamente, como alguém que aparece nas suas estórias de Velhos Amigos. Ela é como a portuguesa Laura de Assunção, teimosa, que ensina o bom caminho a quem está perdido porque é guia certa e certeira, que oferece água fresquinha e fado verdadeiro. E assim como Ecléa quer dizer à Laura, eu quero dizer à Ecléa:

"Você é a amiga que sempre esperei, a quem se pode contar tudo, desde a dor de um sapato apertado até a fraqueza mais risível. Aquela que afasta o sopro dos maus e nos protege" (Bosi, 2003b, p. 88).

Salve, salve, Ecléa Bosi! 


\section{Tribute to Ecléa Bosi}

Abstract: This essay emphacises Eclea Bosi's main contribution to Social Psychology, the relation between theory, method and research techniques on the one hand and, on the other, social, political and cultural militance, starting from the definition of Psychology as the phenomenology of expressive acts and from the relation of friendship between the research and the other as a person.

Keywords: Social psychology. Memory. Other's dignity. Research ethics. Militancy.

\section{Hommage a Ecléa Bosi}

Résumé: Dans cet essai nous avons cherché à montrer la principale contribution d'Ecléa Bosi à la Psychologie Sociale par le rapport établi entre la théorie, la méthode et les techniques de recherche et l'action sociale, politique et culturelle ayant comme point de départ la définition de la psychologie comme phénoménologie des actes expressifs et de l'amitié comme forme de la relation entre le chercheur et l'autre en tant qu'être humain.

Mots-clés: Psychologie sociale. Mémoire. Dignité de l'autre. Éthique de la receherche. Militantisme.

\section{Homenaje a Ecléa Bosi}

Resumen: En este ensayo, buscamos la principal contribución de Ecléa Bosi para la Psicología Social, cuál sea, la relación entre teoría, método y técnicas de investigación y militancia social, política y cultural, a partir de la definición de la psicología como fenomenología de los actos expresivos y de la relación de amistad entre el investigador y el investigado como persona.

Palabras-clave: Psicologia social. Memória. Dignidad del otro. Etica en la pesquisa. Militância.

\section{Referências}

Bosi, E. (1981). Cultura de massa e cultura popular: leitura de operárias (5a ed.). Petrópolis, RJ: Vozes. 
Bosi, E. (1994). Memória e sociedade: lembranças de velhos. São Paulo: Companhia das Letras.

Bosi, E. (2003a). O tempo vivo da memória: ensaios de psicologia social. São Paulo: Ateliê Editorial.

Bosi, E. (2003b). Velhos amigos. São Paulo: Companhia das Letras.

Marilena Chauí, Professora Titular do Departamento de Filosofia, da Faculdade de Filosofia, Letras e Ciências Humanas da USP. Endereço eletrônico: mchaui@usp.br

Recebido em: 10/04/2007

Aceito em: 30/07/2007 
